\title{
Numerical and Experimental Investigations on Performance Optimization of a Microturbojet Engine Combustor
}

\author{
Wu He $\mathbb{C}^{1,2}$ Zhihui Guo ${ }^{1},{ }^{1}$ Siyuan Xu $\mathbb{D},{ }^{2}$ and Yi Jin $\mathbb{D}^{3}$ \\ ${ }^{1}$ School of Energy and Power Engineering, Beihang University, Beijing 100191, China \\ ${ }^{2}$ Beijing Power Machinery Institute, The Third Academy of CASIC, Beijing 100074, China \\ ${ }^{3}$ College of Energy and Power Engineering, Nanjing University of Aeronautics and Astronautics, Nanjing 210016, China
}

Correspondence should be addressed to Wu He; 714028720@qq.com

Received 28 October 2020; Accepted 4 June 2021; Published 22 June 2021

Academic Editor: Antonio Concilio

Copyright (c) $2021 \mathrm{Wu} \mathrm{He}$ et al. This is an open access article distributed under the Creative Commons Attribution License, which permits unrestricted use, distribution, and reproduction in any medium, provided the original work is properly cited.

Sudden extinction of a microturbojet engine combustor was encountered during the engine accelerating process, which motivates the present work to optimize the combustor performance. Numerical results show that by decreasing the primary zone air-introducing area and increasing the dilution zone air-introducing area, the primary zone air percentage is reduced from $39.35 \%$ to $32 \%$, and the primary zone excess air ratio is reduced from 1.122 to 0.915 , which is believed to be beneficial for flame stability both in terms of residence time and rich burn. Meanwhile, the vortex flow pattern in the primary zone varies little as the variations of the airflow distribution. The new engine, which is equipped with the optimized combustor, is tested by experiments. The successful accelerating to the rotating design speed demonstrates the effectiveness of combustor optimization work.

\section{Introduction}

Microturbojet engine combustor features small size, high heat capacity, the short residence time of fuel, and flame stabilizing problem in the full speed range, which makes it a bottleneck in microturbojet engine development $[1,2]$. Although the US has already applied microturbojet engine combustor technology in martial products, such as a series of microturbojet engines produced by TDI corporation, little information on this kind of combustor is available in the literatures [3-5]. Some public researches focus on conventional annular combustor of small and medium size [6, 7]. However, this combustors' design is of limited value to the design of microturbojet engine combustors, with considerations of their difference in size and heat capacity.

Huang et al. [8,9] proposed a convenient criterion to assess if the design of a microturbojet engine can generate thrust; recent development and key techniques of microturbojet engine of the centimeter size were discussed. Huang et al. $[10,11]$ worked on an annular combustion chamber with centrifugal fuel injection and the structure design of a high power density microturbojet engine of $100 \mathrm{~N}$ thrust and $105 \mathrm{r} / \mathrm{min}$ rotational speed. Li et al. [12-17] investigated the performance of a microturbojet engine combustor with numerical methods. The flow structure and temperature distributions were ascertained.

The engine of the presented work is a microturbojet engine with a centrifugal fuel injection system. The centrifugal fuel injection system is renowned for its startup performance with the absence of assistant injectors and high performance with high altitudes. The atomization depends on the rotation speed only. However, the sudden extinction of the engine combustor was encountered during the engine accelerating process.

This paper provides the preliminary design of the combustor and describes the phenomena and data of the sudden extinction during the engine accelerating process. At last, this problem is solved successfully by the optimization of the combustor. Hopefully, the presented work is of some reference value both at the scientific and engineering levels.

\section{Combustor Model and Methods}

2.1. Combustor Model. The inlet air temperature is $479 \mathrm{~K}$; the total fuel-air ratio is 0.0238 . The diameter of the reference cross-section is $150 \mathrm{~mm}$, and the length is $110 \mathrm{~mm}$. According 


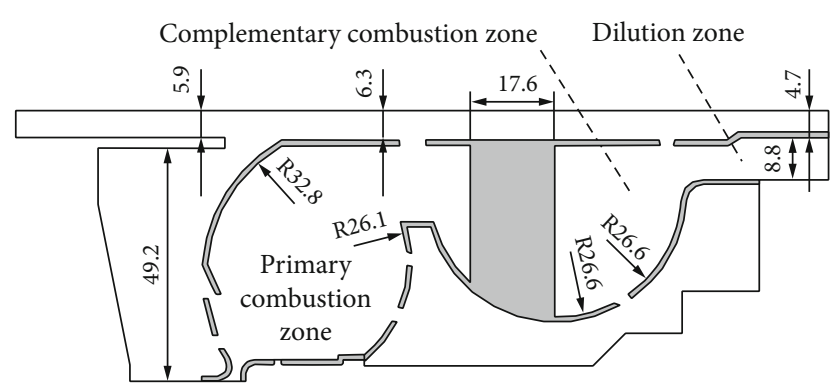

Figure 1: Schematic view for the structure of the combustor.

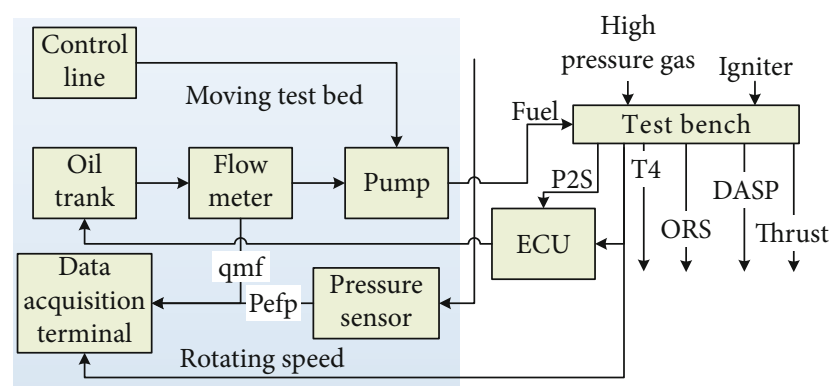

FIGURE 2: Schematic of engine test equipment.

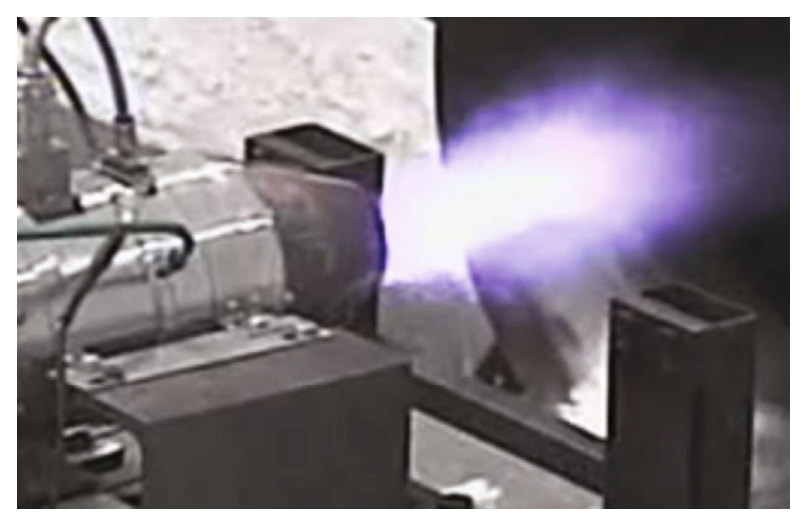

FIgure 3: Photo of a whole engine test.

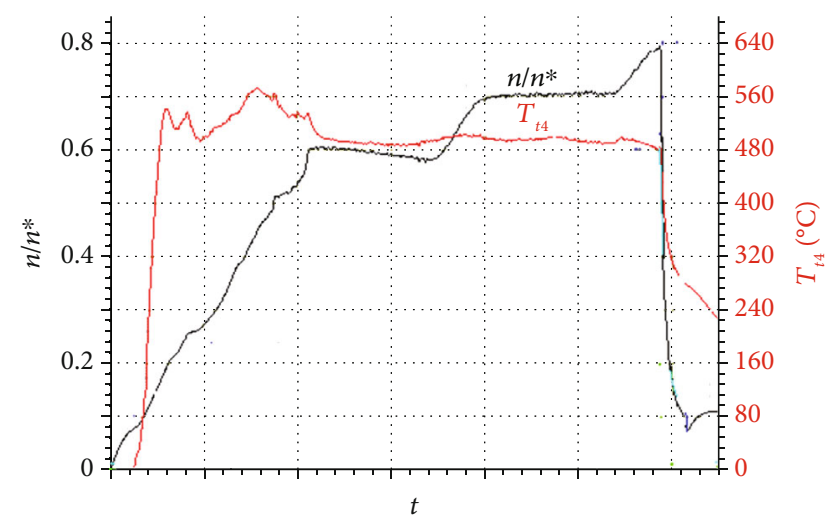

FIGURE 4: Experimental results of engine test with the original combustor.
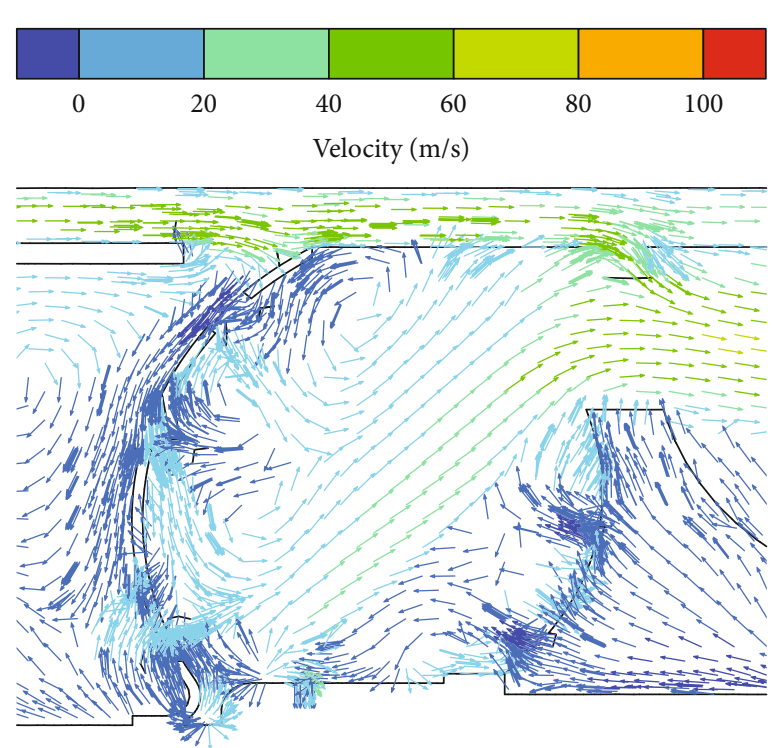

(a)

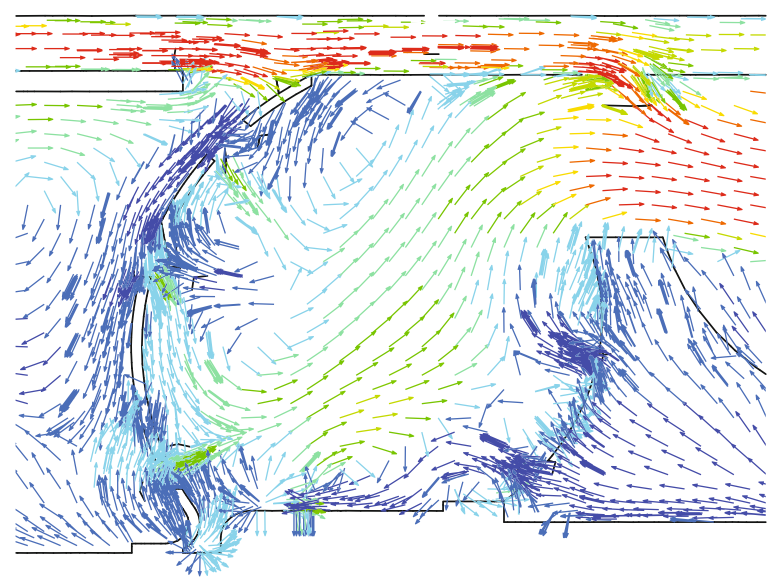

(b)

FIgURE 5: Nonreacting flow computational results at two working conditions: (a) idle design of speed and (b) $80 \%$ design of speed.

to the combustor design parameter, the heat intensity is calculated to be $4823 \mathrm{~kJ} /\left(\mathrm{m}^{3} \mathrm{hPa}\right)$. The equation is given as

$$
Q_{V c}=3600 \xi m_{f} H_{u} /\left(P_{c} V_{c}\right)
$$

where $V c$ is the volume of combustor $\left(\mathrm{m}^{3}\right), \xi$ is the combustion efficiency, $m_{f}$ is the fuel mass flow rate, $H_{u}$ is the low heat value $(\mathrm{kJ} / \mathrm{kg})$, and $P_{c}$ is the average total pressure in the combustor.

It is referred that microengine combustor heat intensity generally lies between 2500 and $4500 \mathrm{~kJ} /\left(\mathrm{m}^{3} \mathrm{hPa}\right)$. The present combustor's heat intensity is so large that it is prone to cause incomplete combustion, flame trailing, and more rugged flow field design. The combustor designed can be divided into the primary combustion zone, complementary combustion zone, and dilution zone. The schematic is shown in Figure 1. 


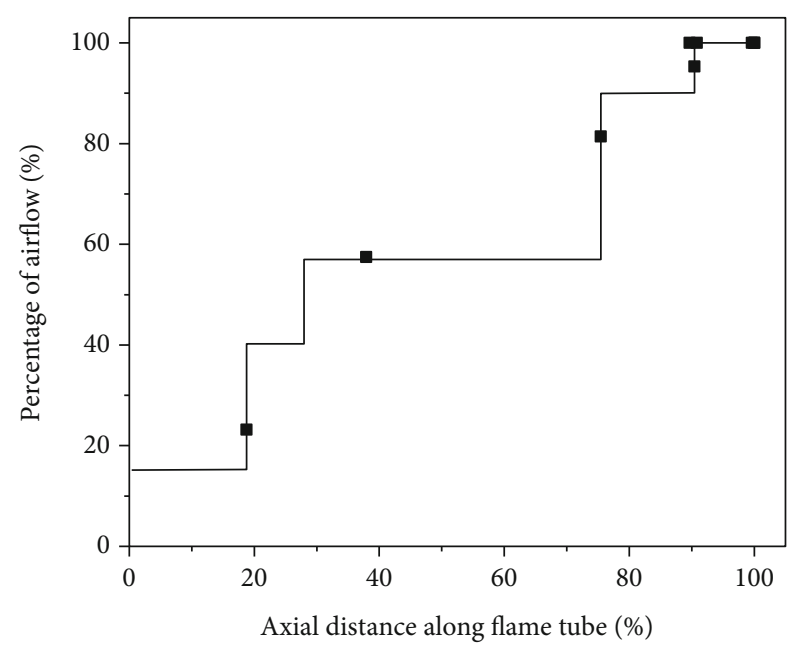

FIgUre 6: Air mass flow distribution along the axial direction.

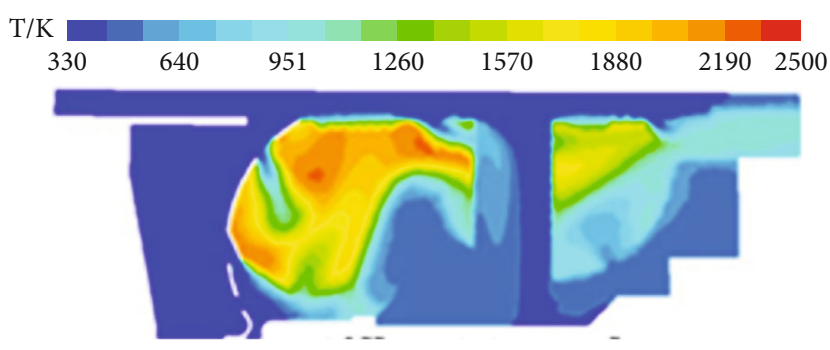

(a) Idle

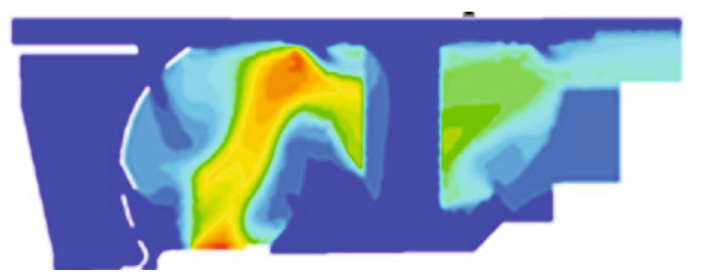

(b) $80 \%$ of design speed

FIgURE 7: Distribution of temperatures at two working conditions.

The importance of the primary zone in a combustor cannot be overstated. The function of the primary zone is to anchor the flame and provide sufficient time, temperature, and turbulence to achieve virtually complete combustion of the incoming fuel-air mixture. An important parameter is the fuel-air ratio of this zone. For microgas turbine engines, fuel-rich combustion, leading a high-temperature rise, contributes to an adverse impact on thermal protection and engine life. In the present work, the combustor's primary zone is designed to be fuel-lean combustion to avoid soot formation, which is considered the small size of the combustor.

In order to keep the airflow rate in the primary combustion zone reasonable, it is necessary to calculate the fuel residence time in this region, making sure of complete combustion. From literature, it is preferred that the fuel residence time in the microengine lies between $5 \mathrm{~ms}$ and $10 \mathrm{~ms}$. It is also preferred that the airflow velocity in the primary com-

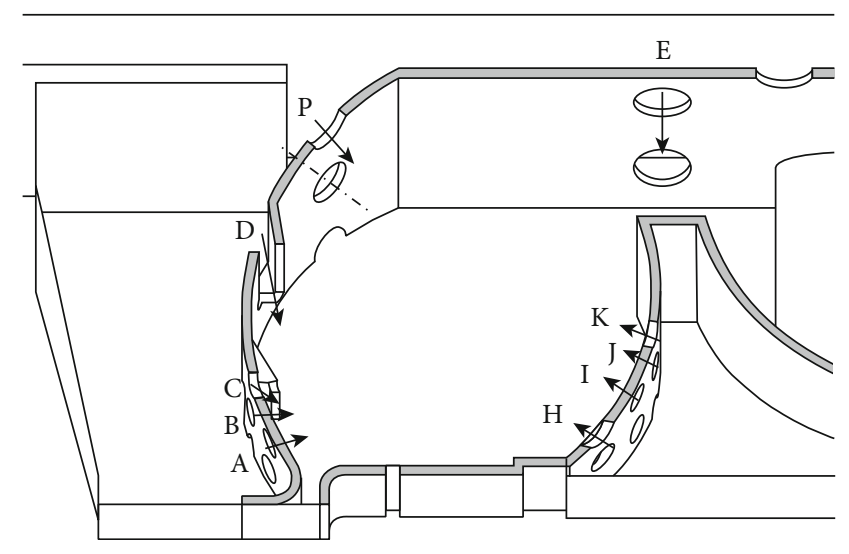

FIGURE 8: Schematics of the combustor liner holing.

bustion zone in the nonreacting flow is usually calculated based on the maximum flame tube sectional area, which is then treated as the mean flow velocity in the flame tube. Additionally, because the engine limits the length of the combustor, it is easy to estimate the length of the flame tube, thus initially calculating the length of the flame tube central line S. According to equations,

$$
\begin{gathered}
\mathrm{m}_{a}=\frac{P_{2}^{*}}{R_{g} T_{2}^{*}} A_{f} v_{f}, \\
\tau=\frac{S}{v_{f}},
\end{gathered}
$$

where $v_{f}=16.49 \mathrm{~m} / \mathrm{s}$ and fuel residence time in the combustor is $6 \mathrm{~ms}$ based on equations (2) and (3).

2.2. Numerical and Experimental Methods. In the present work, the numerical simulations were finished by using commercial CFD software FLUENT. A turbine guide vane is included in the computational model, while the ignitor and the fuel supply tubes are not considered. To simulate the isothermal nonreacting fluid structure, the steady-state continuity and momentum equations are discretized on the numerical calculation with a finite volume method. Turbulence is modeled by the standard $k-\varepsilon$ model. Convection and diffusion terms are discretized by the second-order upwind scheme. The SIMPLE algorithm is applied for pressure-velocity coupling. Periodical boundary conditions are applied to the two lateral sides of the domain. Mass flow and pressure boundary conditions are employed at the inlet and the outlet, respectively. The standard wall functions are utilized to take care of the near-wall region. Grid independence work shows that the computational result varies little as the grid number exceeds 4 million, so that the grid number in the present work is 4 million.

The whole engine experiment is carried out to test the combustor, directly evaluating the combustor design. Figure 2 shows the schematic of the engine test system. The compressor and turbine are started with high-pressure gas, and fuel is pumped from the oil tank with the oil pump, enters the turbine shaft in the engine through the oil 
TABLE 1: Liner hole specification comparison between the basic case and optimized case.

\begin{tabular}{|c|c|c|c|c|c|c|}
\hline \multirow{2}{*}{ Location } & \multicolumn{3}{|c|}{ Basic case } & \multicolumn{3}{|c|}{ Optimized case } \\
\hline & Diameter/mm & Number & Area $/ \mathrm{mm}^{2}$ & Diameter/mm & Number & Area $/ \mathrm{mm}^{2}$ \\
\hline $\bar{A}$ & 4 & 12 & 150.72 & 3 & 24 & 169.56 \\
\hline B & - & - & - & 3 & 24 & 169.56 \\
\hline $\mathrm{C}$ & 5.5 & 12 & 284.96 & 5.5 & 12 & 284.96 \\
\hline $\mathrm{D}$ & 5.5 & 12 & 284.96 & 5.5 & 12 & 284.96 \\
\hline E & - & - & - & 8 & 18 & 904.32 \\
\hline $\mathrm{P}$ & 7 & 12 & 461.58 & 5 & 24 & 471.00 \\
\hline $\mathrm{H}$ & - & - & - & 3 & 24 & 169.56 \\
\hline I & 5 & 12 & 235.50 & 3 & 24 & 169.56 \\
\hline$J$ & - & - & - & 3 & 24 & 169.56 \\
\hline K & 5 & 12 & 235.50 & 3 & 24 & 169.56 \\
\hline
\end{tabular}

supplying tubes in the casing, and finally enters the slinger with the centrifugal force. Combustion is initiated with an igniter when rotation speed reaches the ignition point. During the whole process, rotation speed, pressure behind compressor P2S, the temperature in the flame tube, the temperature in the nozzle, ORS oscillation amplitude, DASP oscillation amplitude, and thrust, and so on are monitored.

\section{Results and Discussion}

3.1. Base Case Experiment Results and Analysis. The whole engine test, as shown in Figure 3, with the initially designed combustor, suggests that the combustor ignition rate of success is $100 \%$, with an ignition delay time of fewer than $3 \mathrm{sec}-$ onds. In the following research process, sudden combustor extinction happens when rotating speed is at $80 \%$ of design speed. The engine test curve is given in Figure 4 , where $n$ $/ n^{*}$ is the ratio of real speed to design speed, $\mathrm{Tt} 4$ is the engine nozzle outlet temperature, and $t$ is the testing time. A more detailed investigation is needed.

It is well known that flame extinction is usually associated with high air velocity; so, it would be reasonable to explore the combustion chamber's flow field. The calculated nonreactive flow field at idle and $80 \%$ design speed are shown in Figure 5. There are some rows of large jet holes and a row of louver holes at the dome, with which a vortex flow pattern is formed to stabilize the flame. However, too large holes feature big air-jet penetrations, which leads to insufficient air/fuel mixing and uniform distribution of fuel/air ratio in the combustion space. As the rotation speed of the engine increases, the penetrations of these big hole air jets increase, making this impact more obvious. As shown in Figure 5, at $80 \%$ of the design speed, the highest air inlet velocity of the jet holes at the dome reaches $75 \mathrm{~m} / \mathrm{s}$. Even when the jet flow comes to the fuel region at the slinger, the airflow velocity is still as high as $37 \mathrm{~m} / \mathrm{s}$, after which the flow direction is changed due to too large oil mist moment at the slinger. Meanwhile, the jet velocity at the louver holes at the root of the dome is about $50 \mathrm{~m} / \mathrm{s}$.

The calculated temperature distributions at idle and $80 \%$ design speed are shown in Figure 6. It can be seen that when the rotating speed of the engine reaches $80 \%$ of the design speed, the strong jets flow through the large holes chill the primary zone of the combustor where is considered to be the place combustion mainly occurs. As the penetration of the hole increases, the chilling effect increases, which may lead to the flame extinction observed during the whole engine test. The temperature comparison is shown in Figure 7 between idle, and $80 \%$ of the design speed confirms this idea. Obviously, at idle speed, the penetration of the jet flow is too small to lower the dome combustion temperature, and the combustion region in the dome remains large. While at high speed, due to increased jet flow penetration, the temperature in most dome areas is too low, and the high-temperature area only exists in a very narrow zone in the middle.

3.2. Optimization Design and Results. The above analysis is believed to optimize the combustor design by decreasing the large dome holes' size. In this way, the optimization may help in two aspects. Firstly, the decrease of the large holes leads to a reduction in the air jet penetration depth, easing the chilling effect discussed above. Secondly, reducing the large holes is also associated with the air mass flow in the primary zone, making the fuel/air mixture richer than the original cases. The schematics of the combustor liner hole are shown in Figure 8, and the specifications of the liner hole of both the primary case and the optimized case are shown in Table 1. It is noteworthy that four rows of holes are added with the optimized case, marked B, E, H, and J, respectively.

The calculated air mass flow rate distribution along the flow direction of the optimized flame tube and the original one is shown in Figure 9. It is found that the airflow distribution becomes more uniform after optimization than before. The air mass flow in the primary combustion zone is changed, from initially $39.25 \%$ to $32 \%$. The excess air ratio in the primary combustion zone varies from 1.122 to 0.915 , closer to the stoichiometric ratio.

Figure 10 shows the flow velocity field of the optimized combustor at $80 \%$ of the design speed. It is known from Figure 7 that the vortex flow pattern constructed by the louver and multirow jet holes in the original flame tube is not destroyed. In the root and top of the dome, airflow in a single louver hole, maximum jet flow velocity, and penetration depth of jet flow are all decreased. As shown in Figure 10, 


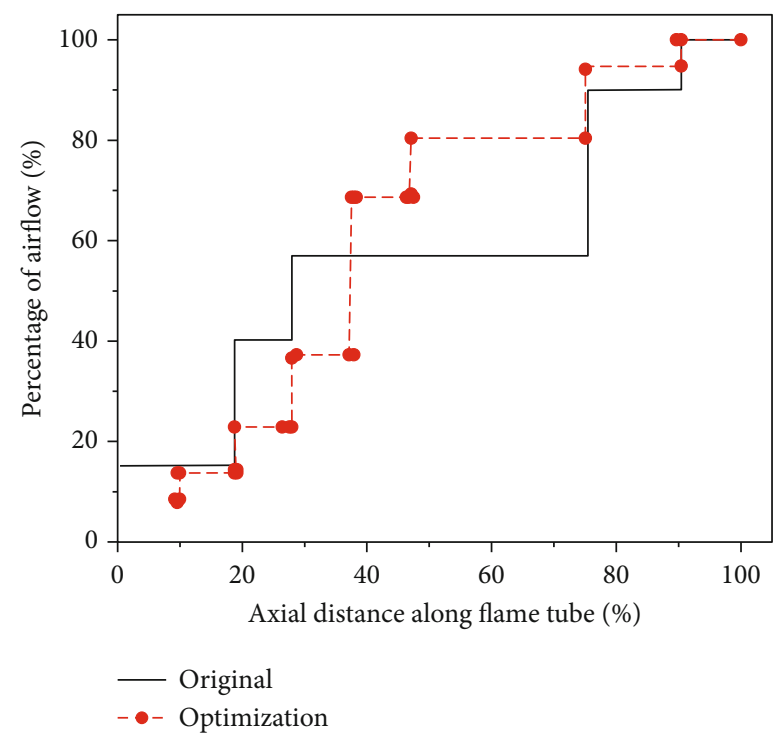

FIGURE 9: Air mass flow distribution comparison between the base case and optimized case along the axial direction.
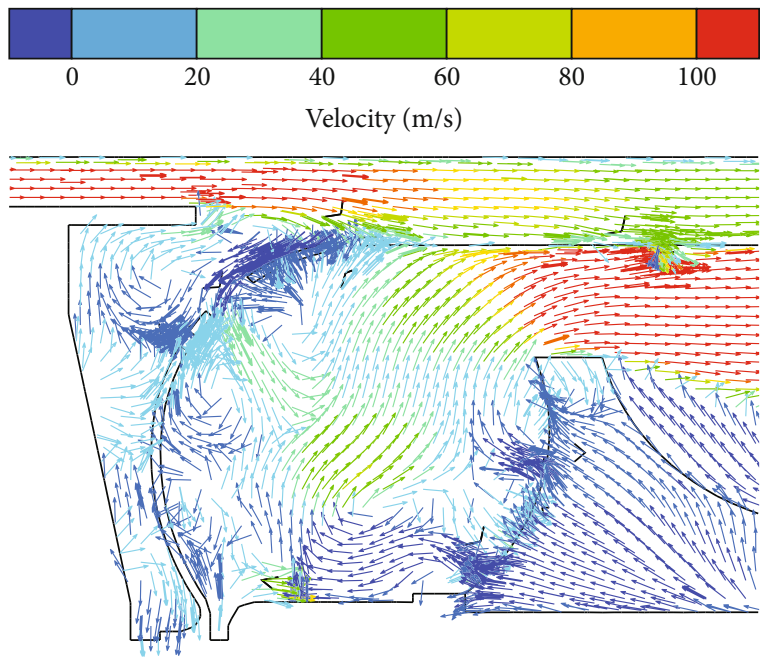

Figure 10: Nonreacting flow computational results at two sections with optimized geometry at $80 \%$ design speed.

the jet hole flow velocity in the top dome decreases from 75 $\mathrm{m} / \mathrm{s}$ to $35 \mathrm{~m} / \mathrm{s}$, while the jet's penetration depth becomes $2 / 3$ of the original. The jet flow's strength in the louver and the root is weakened, preventing the oil mist from being blown off to the inner liner by the two strong jets. The combustion zone in the inner liner is not squeezed, and there is a prominent reflux area between the inner liner and the oil mist. Though small jet holes are increased, the main flow field is not affected by the small holes. As high flow velocity in the little holes, they dissipate quickly due to the small air flow rate.

Figure 11 shows the combustor temperature distribution at $80 \%$ of the design speed. It is suggested that after optimization, even at a very high rotating speed, it still combusts well at the dome combustion which is stabilized.

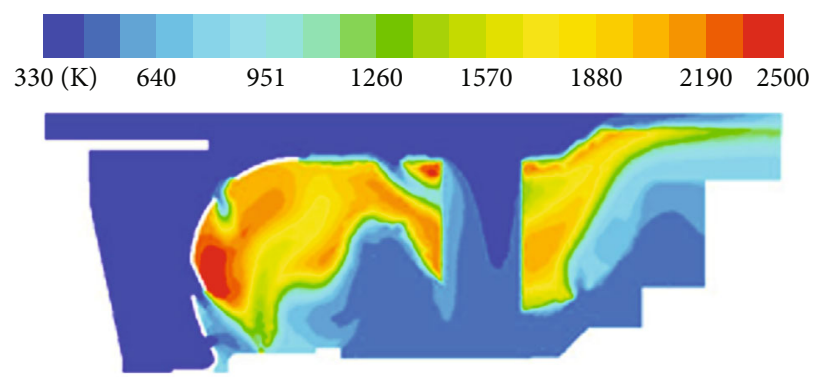

FIgURE 11: Distribution of temperatures at the speed of $80 \%$ design speed.

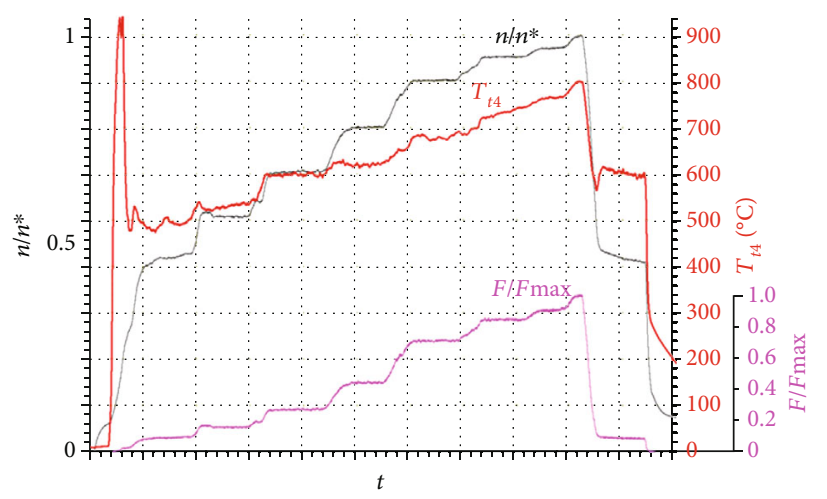

FIgURE 12: Experimental results of the engine test with the optimized combustor.

The complete engine test results with optimized combustors are shown in Figure 12, where $F / F_{\max }$ is the ratio of actual engine thrust to design thrust. The curve indicates that the engine can successfully speed up the design speed, indicating effective combustor optimization design.

\section{Conclusions}

This paper reports a numerical and experimental investigation on the performance optimization of a microturbojet engine combustor. Flame extinction occurs during the engine test, and the reason is attributed to the large holes in the combustor dome, which is associated with immense penetration depth. Optimization of the combustor is accomplished by reducing the size of the large holes. The penetration depth of large holes is decreased, and the fuel-air ratio in the primary zone is increased, helping flame stability. The whole engine test with the optimized combustor features successful speed up to the design speed, demonstrating the optimization's effectiveness for this combustor.

\section{Data Availability}

All data generated or analyzed during this study are included in this article.

\section{Conflicts of Interest}

The authors declare that they have no conflicts of interest. 


\section{References}

[1] H. Tan, "Application status and future development trend of micro turbojet engines abroad," Aerodynamic Missile Journal, vol. 3, 2013.

[2] S. Choi, D. Lee, and J. Park, "Ignition and combustion characteristics of the gas turbine slinger combustor," Journal of Mechanical Science and Technology, vol. 22, no. 3, pp. 538$544,2008$.

[3] M. M. Harris, A. C. Jones, and E. J. Alexander, "Miniature turbojet development at hamilton sundstrand the TJ-50,TJ-120 and TJ-30 turbojets," in 2nd AIAA "Unmanned Unlimited" Conf. and Workshop \& Exhibit, pp. 1-9, San Diego, CA, USA, September 2003.

[4] C. Rodgers, "Turbofan design options for mini UAV's," in 37th Joint Propulsion Conference and Exhibit, San Diego, CA, USA, July 2001.

[5] Y. Guo, K. Liu, and Z. Yan, "Design difficulties and top-level system analysis of micro turbojet engine," Aerodynamic Missile Journal, vol. 12, 2010.

[6] Y. Zhou, W. Shao, and J. Wang, "Flow field computation for turbofan engine combustion chamber," Journal of Propulsion Technology, vol. 22, no. 6, pp. 480-482, 2001.

[7] F. Shi and X. Liu, "Aerothermodynamic numerical simulation of integrated small turbofan engine system," Journal of Propulsion Technology, vol. 21, no. 2, 2000.

[8] G. Huang, Q. Wen, and B. Li, "Research on top-level design of micro turbojet engine," Journal of Aerospace Power, vol. 18, no. 6, 2003.

[9] D. Liang and G. Huang, "Recent development and key techniques of micro-turbine in centimeter size," Gas Turbine Experiment and Research, vol. 17, no. 2, 2004.

[10] Z. Huang, P. Shan, and Y. Wang, "Structural design study of a micro-turbojet engine," Journal of Beijing University of Aeronautics and Astronautics, vol. 30, no. 3, 2004.

[11] C. Zeng, H. Wang, and P. Shan, "The design and study of the annular combustion chamber with centrifugal fuel injection," Journal of Aerospace Power, vol. 18, no. 2, pp. 92-96, 2003.

[12] C. Li, S. Fang, and P. Zhang, "Numerical simulation of annular combustion chamber for micro turbine engine," Journal of Propulsion Technology, vol. 29, no. 5, 2008.

[13] Z. Hu, Aeroengine Design Manual Volume 9: Main Combustion Chamber, Aviation Industry Press, 2000.

[14] H. Maskey and F. X. Marsh, "The annular combustion chamber with centrifugal fuel injection," in SAE Technical Paper, Detroit, Mich, 1962.

[15] S. Song, R. Jiang, J. Chen, and D. Liang, "Performance experiment of a reflection flow annular combustor with slinger," Journal of Aerospace Power, vol. 22, no. 9, 2007.

[16] S. Song and L. Hui, "Analysis on the characteristics of centrifugal oil-swinging plate," in The 3rd Symposium on Power and Transmission of Chinese Aviation Society (Helicopter), Wenzhou, 2000.

[17] C. Xiong and S. Song, "Experimental study of atomization performance on a fuel slinger," Journal of Aerospace Power, vol. 7, 2012. 